\title{
STUDIES ON THE LIFE HISTORY OF PROTOZOA.
}

\author{
IV. DEATH OF THE A SERIES.
}

\section{CONCLUSIONS.}

\author{
BY
}

GARY N. CALKINS.

With 3 Plates and 3 Figures in the Text.

Experiments on the life-history of Paramocium caudatum have now been carried on continuously for 29 months. Two series, designated as the "A series" and the "B series," were started on the first of February, 190I, with individuals from different sources. The B series died out in May, 1902, in the 57 oth generation; the A series on December 19, I902, in the $742 \mathrm{~d}$ generation. A third series- "C" was started in June, I902, with an individual from Cambridge, Mass., and died out in June, 1903, in the 379th generation. The progress of the first two series has been recorded from time to time, ${ }^{1}$ and in the present paper I wish to give the history of the last cycle of the A series and to consider the results in relation to some general biological problems and theories.

I. THE JUNE AND DECEMBER (I9O2) PERIODS OF DEPRESSION.

As described in the earlier Studies (I and III) the general vitality of the two series, $A$ and $B$, as expressed by the daily division rate, underwent periodic cycles of vigor and depression.

${ }^{1}(\underline{1})$ Studies on the Life History of Protozoa. I. The Life Cycle of Paramœcium caudatum. Archiv. f. Entwk. XV, 1, 1902.

(2) Studies, etc. II. The Effect of Stimuli on the Life Cycle of Paramœeium caudatum. (With C. C. Lieb). Arch. f. Protistenkunde. I, 1, 1902.

(3) Studies, etc. III. The 620th Generation of Param. caud. Biol. Bull. III, 5, 1902. 
The early curves appeared to indicate a periodicity of threemonth intervals, and this was taken to be the time of the usual life cycle in culture of Paramocium caudatum; this conclusion was based partly upon my own results and partly on those of Joukowsky and of Simpson, both of whom found that cultures of this infusorian died out after three months of treatment. It was found, however, and it may be seen from the now completed curve of the A series (see Diagram I) that trimonthly periods of depression were not fatal and that recovery occurred without purposeful stimulation. Thus in the first apparent depression (May, I901,) the recovery was thought to be due to the stimulation by jolting on a railroad trip of six hours; another in March, 1902, was considered due to a slight rise in temperature. These periods of depression differ markedly from those of August and December, I90I, and of June, I902, when the individuals continued to die at a high rate, notwithstanding repeated jolting experiments, increase in temperature, and the like, and the race was saved only by change to a special diet after numerous attempts and failures with foods of different kinds. The wellmarked cycles, therefore, with periods of depression which demanded stimulation of a decided character, were approximately of six montbs' duration, while intermediate cycles of less importance were about three months long. The first of the six-month cycles ran from February I, I90I, to August I, I90 I, (see Diagram I); the second from August I 5 to January I, 1902; the third from January I to July I, and the last from July to December I9, I 902. During the first three cycles the number of generations was nearly the same (200, I98 and 193, respectively), the last, on the other hand, was much less, the individuals dividing only 126 times.

The stimulation which resulted in the renewal of vitality after the periods of depression in August and December, IgOI, was due to the change from hay infusion diet to beef extract for a limited period (see Studies I and III). The same change failed to work in the July, I902, period of depression, and after the race had become reduced to only six individuals, a successful substitute for the beef extract was found in the extracts of pancreas and brain (see Studies III). Recovery, however, was not so 
successful as in the previous periods and the organisms were much less vigorous than at similar periods in previous recoveries. The division rate, furthermore, slowly fell from the relatively high point in August, and gradually decreased during the fall months until the $A$ series died on the Igth of December. The B series had succumbed in the 570 th generation, in June, before the right stimulus was found. Except for the slowness of divisions the organisms appeared perfectly healthy during the summer and fall of 1902, although microscopical study of preparations made during this period showed characteristic changes in the protoplasmic structure (see Figs. I8 to 21). The organisms were plump and moved freely about the slide, responding with customary vigor to stimuli of different kinds. Every precaution was taken during this period to invigorate the race and every experiment that my ingenuity could devise was executed; some appeared to give a temporary improvement but none was permanent, and the last individual of the A series finally died after 23 months of continued daily observation, without, however, any morphological evidence of general senility. (See Diagram I.)

\section{UNSUCCESSFUl ATTEMPTS TO REJUVENATE THE A SERIES IN THE FINAL PERIOD OF DEPRESSION.}

Artificial rejuvenation of the A series was successfully accomplished three times. The experiments and results have been described in other places, and it will be sufficient here to merely point out that after considerable experiment, beef extract was successful in the first two cases and pancreas and brain extract in the third, the result being due, probably, to the change in salt contents of the medium. The approaching end of the series was indicated some time in advance by the reduced division rate during the fall of I902, and efforts were continuously made to rejuvenate them during this period. For these experiments all of the stock of the regular series was maintained, and the number of lines under observation frequently ran up to twelve or more. The results of all experiments were tabulated and the effects of the stimuli used were noted for comparison with the regular series. The general result may be seen upon the diagram which 


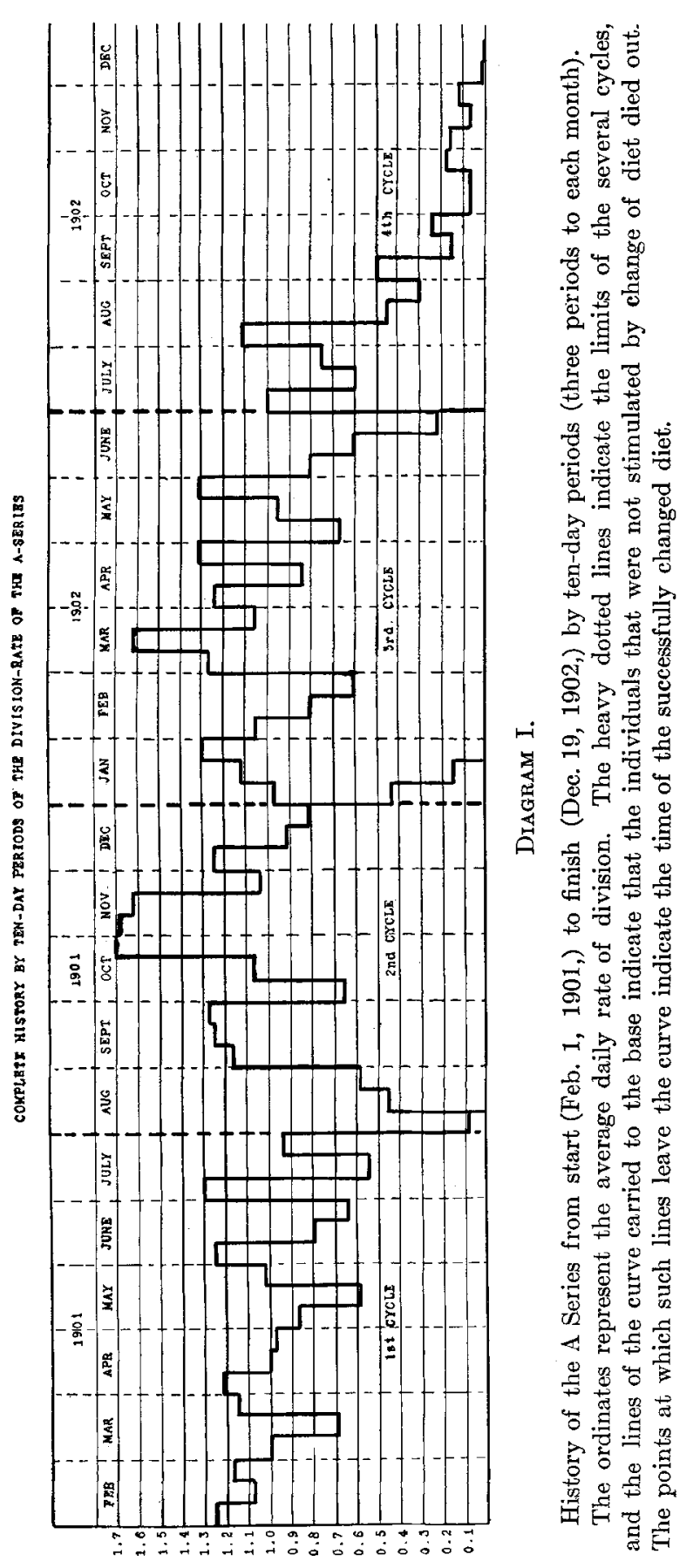


hows that, despite all efforts to stimulate, the race rapidly weakened and ultimately died.

\section{Experiments with Extracts.}

a. Beef Extract. During the last autumnal period, beef extract was used at different times in the same way that it had been used successfully during previous periods of depression, and for the same length of time, twenty-four hours. The organisms were immersed in the fluid full strength in the majority of cases, but experiments with the half strength were also made. The failure of the beef treatment in June, I902, has already been described (Studies III) and I shall consider in this place only the experiments subsequent to that time. In general it may be stated that beginning with the treatment in May, the effect of the beef extract was nil. On the rgth of June $A_{3}$ and $A_{4}$ were immersed as usual and for the same length of time. Both of them died before the 27th. Again on the 22d $\mathrm{Al}_{1}$ and $\mathrm{A}_{2}$ were treated, and both of these died on the 26th. Similar results were obtained in all later experiments, as shown by the following résumé:

July 6. $A_{3}$ and $A_{4}$ treated. Both died before the $5_{5}$ th.

July 24. AI, A2, $A_{5}$ "AI and $A_{2}$ died on 25th. $A_{5}$ on the 26 th.

Aug. 2. AI and $\mathrm{A}_{2}$ " " Both died before the I 9 th.

Aug. 2. A5 and A6 " Both died before the ${ }^{3} 3^{\text {th. }}$

Nov. 26. A5 " " Died on the 27th.

Nov. 26. A7 " " Died on the 29th.

Nov. 26. AII " " Died December 2.

Nov. 28. A6, A8, A9 and AI2 treated. Died before December 4.

The short time in beef may not have been long enough to make the change beneficial; with this in mind I kept the last few individuals in for three days (Nov. 26, 27, 28). Not one of them divided more than once and all died within a week. Beef extract, therefore, had lost its potency as a rejuvenating medium.

The effect of beef extract upon the body structures was to increase the number of gastric vacuoles; while, in some cases, the micronuclei were caused to divide (Figs. 5 and 6). Even in May, I902, there was an indication of the endoplasmic concentration 
which accompanied depression at this period. The dense condition of the protoplasm is better shown in Fig. 6 which represents an individual twenty-four hours after transference from beef extract into hay infusion. It may be noted here that, at this period, the beef extract failed to reduce the dense endoplasmic condition to one of tenuity which seems to be the normal condition.

b. Extract of Pancreas. Extract of pancreas was made in the same way as the beef extract. A fresh sheep's pancreas was cut in small pieces and brought to boiling point in water. After filtering and cooling, the Paramacia were placed in it and left for 24 hours, as in the beef. At first it proved a good substitute for the beef and the organisms appeared to thrive on it; but later, in November and December, it was as useless as the beef. The following records show this fact:

June 27. $A_{3}$

June 29. AI and $A_{2}$

July r6. $\mathrm{A}_{4}$

July i 7. A6

July I8. $\mathrm{A}_{1}, \mathrm{~A}_{2}$ and $\mathrm{A}_{4}$ "“

July 20. Ar, $\mathrm{A}_{2}$ and $\mathrm{A}_{4}$ “"

Aug. 20. A2

Aug. 20. A8

Dec. 8. A5, A6, $A 7$ and $A 8$ treated. No divisions. All died out on Igth before or after treatment with various other substances.

At the period in June when recovery was effected by using the extract of pancreas, the organisms of both series were in the condition represented by Fig. 7. The endoplasm was densely granular and homogeneous, and had a curiouslv "stuffed" appearance. This condition was relieved by using extract of pancreas, whereas beef extract, made with the same water and in the same way, was ineffectual. Figs. 8, 9 and ro show the general course of the 
action of the pancreas extract. Fig. 8 represents an individual twenty-four hours after treatment, i.e., after change from pancreas extract into hay infusion. ${ }^{1} \quad$ The characteristic dense structure is distinctly shown, but in the center there is unmistakable evidence of the normal condition. Figs. 9 and to represent two individuals forty-eight hours after treatment with the pancreas extract. In the former, the characteristic dense structure is still visible at the two ends, but the center is clearing. In the latter, new gastric vacuoles have appeared in the endoplasm, the animal being well on toward recovery when killed.

c. Extract of Sheep's Brain. This was made in the same way as the other meat extracts, and the animals were similarly treated with it. It was not efficient as a permanent stimulant, and was discarded in subsequent treatment.

d. Extract of Mutton. "Mutton Broth." This extract was also tried in the summer (July 20 and 23), but in no case was it successful, the organisms invariably dying within 24 hours.

e. Lecithin. A trace of pure lecithin was put into the regular hay infusion during the week of August 20. The organisms were apparently not injured by the change, but did not live more than 48 hours after the treatment.

f. Pineapple Extract. With the view of ascertaining if some of the vegetable ferments might not prove beneficial, I tried extract (juice) of fresh pineapple, and of fresh apple. A4 was put into dilute pineapple juice July 27. The reaction was well marked, as shown by decided increase of movement and by three divisions in the ensuing 48 hours. The experiment was repeated the next day with a like result. It was repeated again August 3, but was unsuccessful, the organisms dying two days after treatment. The stimulation was temporary in all cases, and it should be noted that the organisms were in a period of increasing vitality when the first pineapple treatment was given (see Diagram I).

\footnotetext{
${ }^{1}$ The hay infusion was made every day, the same amount of hay and water being taken each time and raised to the boiling point. This method was never varied during the entire period of the cultures and the salt content of the water, as shown by weekly analyses, did not vary beyond a very slight fraction of one part to one hundred thousand.
} 
g. Apple Fuice. A piece of fresh Porter apple was allowed to lie for a few minutes in the hay infusion. In this case the result was well marked, and a decided stimulus was noted. Again, on Sept. 20, A5, A6, A7 and A8 were all put into one drop of apple juice to 12 drops of hay infusion and left for thirty to forty-five minutes. They were then transferred to clear hay infusion and left. All divided the next day. The experiment was repeated on the 21st with a like result. In some cases the organisms died immediately, showing that the strength used was too great. When properly diluted, however, apple seemed to give a satisfactory temporary stimulus, although in no case did the stimulation last for more than forty-eight hours. The same experiment tried in October gave no results; the organisms died.

In addition to the above, various proprietary mixtures were tried from time to time. Among these were phospho-albumin, and nuclein-albumin; none gave satisfactory results.

\section{Experiments with Acids and Salts.}

In view of the successful results which have followed experiments with ions in connection with egg development, it was thought that perhaps dilute acids or salts would have a beneficial result in the case of these weakened infusoria. Normal solutions were made in each case and various strengths were tested from those that would kill to those that only slightly stimulated. The organisms were left in the fluids for only a short time (20 to 30 minutes) and were then transferred to fresh hay infusion. Attention may be called here to the fact that potassium phosphate when used in this way was successful in restoring the vitality of weakened Paramocium in the preceding December cycle, the "rejuvenation" which resulted was directly comparable with that effected by the beef extract. There was reason, therefore, to believe that the repeated use of various salts would give satisfactory results in the last period of weakness of the race. This expectation, however, was not realized for none of the chemicals used in the fall and winter of 1902 was successful in this way; all were as futile as the beef and pancreas extract, as shown by the following experiments: 


\section{A. Potassium Salts.}

a. $\mathrm{K}_{2} \mathrm{HPO}_{4}$. On the 8th of June, 1902, one individual from the line of $A_{2}$ was treated for 30 minutes with a solution of dibasic phosphate of the strength of one drop of $\frac{n}{1250}$ to six drops of usual hay infusion. The result was a marked increase in the rate of division for a considerable period as compared with the control series, as follows:

Average daily division-rate for 5 -day periods, June 8-July 5 .

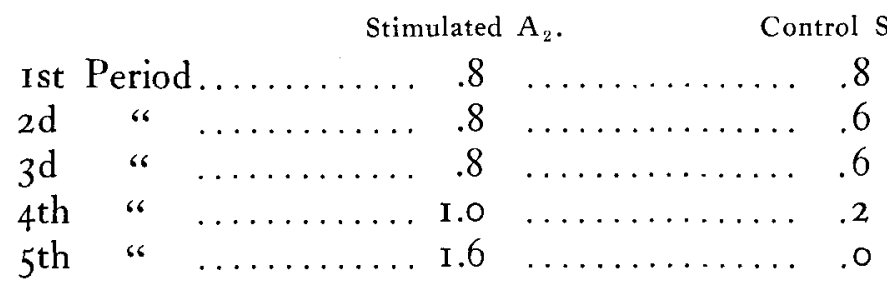

On the $27_{\text {th }}$ of June the above experimental series was substituted in the regular culture series and the descendants of these individuals formed the regular lines until the final extinction, subject, of course, to the other experiments as stated elsewhere.

A stronger solution (I-5) and for a longer period (I hour) was used with $\mathrm{A}_{3}$ on June 26 . The individual died in three hours. On August $2 \mathrm{r}$ the same strength was used, but for only 25 minutes; the individual died in four days without dividing. The general effect of this salt was, therefore, favorable, with evidence that a certain optimum strength is alone beneficial. The beneficial effects upon the endoplasmic structure are shown in Figs. II and I3.

b. $\mathrm{KH}_{2} \mathrm{PO}_{4}$. Experiments with the monobasic salt were also made and various proportions were used, but none was successful.

c. $K C N$. Various proportions of $\frac{\mathrm{n}}{50}$ of this salt were used, the most successful being one drop of the solution to twelve drops of hay infusion. This was not strong enough to kill the bacteria which afford the only food for Paramceium. Four individuals were immersed October 29 in the mixture and left for 24 hours. At the end of this time each had divided once, while none of the control series had divided. Of the eight individuals resulting from this treatment, four were placed again in the $\mathrm{KCN}$ solution, 
(made fresh), while the other four were placed in hay infusion without the salt. Of the former set, each individual divided once in 48 hours, and of the latter set, one died, two divided once, and one divided twice in the same period. The regular control series did not divide at all during this time. Both sets were placed in hay infusion on the fourth day and neither set continued to live, all died before the sixth of November. Another set of four individuals were treated with the salt every day for the same period. After the first 24 hours none had divided; after the second 24 hours each one had divided once. This was November 2. On the $4_{\text {th }}$ all had divided twice, on the 6th only one had divided again, on the 7 th another one had divided, on the 8th none had divided again, on the gth one died, while the rest did not divide, on the Ioth two others died, and the remaining one was placed in the usual hay infusion without the salt, having been treated daily for ten days with it. It did not divide again until the $\mathrm{I} 8 \mathrm{th}$, and finally died out on the $2 \mathrm{Ist}$. Others, however, that had been treated, and had been placed earlier in hay, continued to live and supplied the regular lines of the experiment. The use of the KCN therefore can be said to have been successful to a limited extent, and, possibly, to have prevented an earlier extinction of the race. The effect on the curve of the life cycle is shown by the temporary rise during the last period in October and the first period in November.

d. $K O H$. This was tried only once with four individuals on the 28 th of October. $\frac{\mathrm{n}}{40 \overline{0}}$ I part to 4 was used for 30 minutes. On the first of December two had died and one had divided once. None divided again and all of the individuals experimented with died before the fourth of November.

\section{B. Sodium Salts.}

a. Dibasic Sodium Pbosphate. Three individuals, AI, A3 and $\mathrm{A}_{4}$ were placed for 30 minutes in $\frac{n}{2 \frac{n}{5}} \mathrm{Na}_{2} \mathrm{HPO}_{4}$. All died without dividing by the $27 \mathrm{th}$. The experiment was not repeated.

b. Sodium Tartrate. July Io two individuals were placed for 30 minutes in $\frac{n}{50}$ sodium tartrate, one drop to five of hay infusion. 
They died in twenty-four hours. The experiment was repeated on July 14, three drops to five of hay infusion being used. On the $15^{\text {th }}$ they did not divide, on the 17 th they divided once, and died on the I8th. Experiment not repeated.

c. Sodium Chloride. This salt was used on several occasions with negative results as a rule. (See, however, table below.) In September, 1902, when the race was comparatively vigorous, an individual was treated for 30 minutes with $\frac{\mathrm{n}}{50} \mathrm{NaCL}$, one drop of the salt to twelve of the hay infusion. At the end of 48 hours it had divided once, but died within five days without further division. The effect upon the protoplasmic structure was not particularly noticeable (see Fig. 18).

The following table gives a comparative view of the efficiency of different salts on the division rate for thirty days subsequent to treatment. Several individuals of the A series were treated on the 2oth of March with potassium phosphate and the progeny of one of these in the 78 th generation were again treated in part on May 6 with potassium phosphate, and in part, with potassium chloride, magnesium chloride, sodium chloride and calcium chloride with the strengths, and for the times indicated. The following notes were made at the time of the treatment. "When the individual was put into the potassium chloride it began at once to swim backward with great rapidity, and continued this for about five minutes. It then straightened out and appeared perfectly normal in the solution. When returned to the hay infusion at the end of the treatment, it went through the same convulsions but soon became normal, perhaps slightly swollen and transparent." Again: "When the individual (another individual of course) was put into the magnesium chloride solution it was hardly affected in any way, a very slight increase in movement being noticed." Again: "Treatment with $\mathrm{NaCl}$ did not affect the individual, it appears fat and happy in the hay-infusion." Again: "Very much affected by the $\mathrm{CaCl}_{2}$ solution. One of the three specimens died; the other two were distorted and badly shrunken, this lasted for at least fifteen minutes after they had been transferred to the hay infusion." 
Average number of divisions per day after stimulation.

\begin{tabular}{|c|c|c|c|c|}
\hline May 6-Io....... & $\begin{array}{c}\mathrm{K}_{2} \mathrm{HPO}_{4} . \\
\mathrm{I} .60\end{array}$ & $\begin{array}{l}\mathrm{KCl} \\
\mathrm{I} .00\end{array}$ & $\begin{array}{l}\mathrm{MgCl}_{2} \text {. } \\
\mathrm{I} .00\end{array}$ & $\begin{array}{c}\mathrm{CaCl}_{2} \text {. } \\
0.60\end{array}$ \\
\hline May II-I $5 \ldots \ldots$ & I.OO & 1.20 & 0.60 & 1.20 \\
\hline May $16-2$ I ....... & I. 50 & 1.50 & 1.00 & $1.5^{\circ}$ \\
\hline May 22-26. . . . . & 1.80 & 2.00 & I.80 & 1.80 \\
\hline May 27-June I.... & 1.25 & I.03 & 1.25 & 0.75 \\
\hline June $2-6 \ldots \ldots \ldots$ & $\mathrm{r} \cdot 33$ & I.33 & I.33 & 0.16 \\
\hline June $7-12 \ldots \ldots$ & $\begin{array}{l}0.20 \\
\text { dead }\end{array}$ & $\begin{array}{l}0.40 \\
\text { dead }\end{array}$ & $\begin{array}{c}1.60 \\
\text { living }\end{array}$ & dead \\
\hline
\end{tabular}

All were normal solutions, diluted 25 times, one drop to twelve drops of hay infusion and the treatment lasted for 30 minutes in case of $\mathrm{KCl}$, and for 25 minutes in each of the other solutions. Definite conclusions cannot be drawn from one set of comparisons for it may have been pure accident that the magnesium chloride specimens continued to live. The effect of $\mathrm{MgCl}_{2}$ upon the protoplasmic structures is shown in Fig. I2.

Comparatively few experiments were made with acids. Hydrochloric and nitric acids were tried during the period of depression in October, 1902, but the results were negative, the individuals dying within twenty-four to forty-eight hours. An interesting effect was produced by treatment with dilute phosphoric acid. The dense endoplasm was broken up and with it the macronucleus which, after the treatment, appeared as many small fragments (see Fig. 16).

Of the other unsuccessful attempts to rejuvenate the race during the last period of depression I will mention only those with galvanic stimuli, with nitro-glycerine, and with dried and powdered Paramocium of an entirely foreign race.

\section{Galvanic Stimuli.}

A small cell was made and connected with two Mesco batteries. Four individuals were treated on November 28, three different times to the full current and for a period of one minute each time. The usual reaction followed the treatment, migration to the negative pole, and when the current was reversed, migration from the 
positive to the negative pole. At the end of the treatments the four individuals appeared normal. On the following day one had died, another on the ensuing day, and the last two on the fourth day. Another time the same experiment was tried but with only one minute of exposure. The result was the same, death without division. The death of these organisms at this time cannot necessarily be ascribed to the treatment, for a glance at the diagram shows that the entire race was dying and that divisions were infrequent in all cases.

\section{Nitro-Glycerine.}

At the suggestion of Professor Wilson, and as a last resort, I tried two experiments when the race appeared to be dying out in December. Nitro-glycerine in very weak solution (unfortunately I have no record of the strength used) was put into the hay infusion. It made no appreciable difference in the final result and the organisms did not divide.

Professor Wilson's other suggestion seemed more hopeful, on the $a$ priori ground that renewal of vitality is effected by the union of two individuals. A culture of Paramocium fresh from pond water was made, and hundreds of individuals were allowed to dry in a small drop of water in a watch crystal. When dried the remains were scraped together and pulverized, the powder thus formed being added to the hay infusion in which the weakened Paramacium were kept. Although this extremely ingenious suggestion was worthy of a fruitful result, the outcome of the experiments was the same as with all the rest, and not a single individual lived after the Igth of December, one week after sixday treatment with the dried Paramocium.

There remain many experiments that might have been tried, and that might possibly have accomplished the same results that were obtained in the earlier periods of depression when the race was successfully reinvigorated by artificial means, and even the experiments that were tried might have been successful if different strengths, or times of action, had been used. Many suggestions were made by my colleagues and other friends, especially in regard to the trial of some chemical compound. I am pleased to 
acknowledge the friendly and scientific interest which prompted these suggestions, and desire to state that if they were not always carried out, it was because of the limits of my time and of the constantly decreasing number of individuals left to experiment with. It was my desire to try as many classes of experiments as possible, and some of these might have been successful if tried at an earlier time or if carried out on a sufficiently large scale, but here again the scarcity of living material would not allow the continued experimentation along lines that were fruitless on the first trial. It must be remembered that such experiments, to be of any value in a work like this, had to be made on the material that had been under constant observation for nearly two years, and preliminary experiments with fresh forms from the ponds were valueless so far as indicating the effect on the vitality of the race under observation.

\section{PROTOPLASMIC STRUCTURES OF PARAMCECIUM.}

\section{The Normal Paramcecium.}

The usual size of a normal Paramacium is from 200 to 300 microns, and the form is fairly constant, warranting the designation."slipper animal." In all of the preserved specimens that I have made from time to time, the fixing fluid was saturated corrosive sublimate to which was added 10 per cent of glacial acetic acid. Having a common method of fixation the different individuals can be compared point by point.

a. The Endoplasm. The endoplasm of a normal form is made up of various granules of different sizes, of vacuoles and crystals (Fig. I). When the animal is moving about in a nutrient medium it constantly takes in food with the water absorbed. The food of Paramecium consists of bacteria, and these accumulate in a gastric vacuole until the latter has attained a certain size when, according to Wallengren, ${ }^{1}$ it is caught up in the endoplasmic flow and carried to the posterior end of the body. It then moves anteriorly toward the left side, ultimately passing over to the right and then down on the right side. In this migration of

${ }^{1} \mathrm{H}$. Wallengren. Inanitionserscheinungen der Zelle. Zeit. f. Allg. Physiologie I: 1, 1901 . 
the vacuole the food is brought into the immediate vicinity of the macronucleus where the effect of the nuclear environment is shown by the immediate acid reactions with congo-red of the vacuole contents (Wallengren). The food material in such a vacuole is massed into a more or less homogeneous body corresponding to Greenwood's observation on Carchesium, and in this condition the digestive fluids work upon it to resolve it into digestible and indigestible parts. After this the soluble portions are absorbed and the residue defecated. The soluble portions pass into the endoplasm to be stored up as reserve food (Wallengren) from which they are taken as the need comes to be made into living molecules.

The processes of digestion thus given rise to definite elements in the endoplasm, elements which react to stains in characteristic ways. In addition to these, however, we might expect to find waste matters due to incomplete oxidation as well as final products of metabolism in the form of crystals, etc. The various possibilities of this nature have given rise to different interpretations upon which my own observations throw but little additional light. With neutral-red acting upon the organism when alive, Prowazek ${ }^{1}$ distinguished three kinds of granules in the endoplasm: (I) The food balls; (2) Small round granules which are distributed throughout the periphery more or less uniformly (Prowazek actually found them at the two extremities and about the mouth); (3) Minute granules distributed throughout the endoplasm and all over the body.

The minute peripheral granules (No. 2) are interpreted by Prowazek in the same way that Wallengren had previously interpreted similar bodies in Pleurocoptes bydractinice, viz., as excretory vacuoles with a solidified granule of excreta within them. Pütter, ${ }^{2}$ on the other hand, interpreted them as basal bodies of centrosome nature lying at the bases of cilia. Wallengren subsequently showed, however, that the granules in question are not at the bases of cilia but lie beside the cilia, and that rows of these granules alternate with rows of cilia. He interpreted them as the

' Vitalfärbung mit Neutralrot an Protozoen. Z. wiss. Zool. Bd. 63, 1898.

${ }^{2}$ Studien über Thigmotaxis bei Protisten. Arch. f. Anat. u. Phys. 1900. 
papilliform external swellings of the trichocysts and as merely condensed peripheral portions of the cortical plasm. My own observations support those of Wallengren.

The third type of granule is interpreted by Prowazek as a ferment or enzyme bearer. Pütter, on the other hand, believes them to be "respiratory granules" owing their staining capacity to the contained carbon dioxid. Wallengren's observations on starving forms led him to the belief that neither interpretation is correct, for, he argued, these granules being the first to disappear in hungry forms must be of the nature of stored food (see Figs. 23 and 24).

The crystals which are found in well-fed forms were identified by Schewiakoff as metaphosphate of calcium. They are of various forms and sizes and are confined to the endoplasm; being crystalline in nature they cannot be mistaken. They are now generally regarded as late metabolic products resulting from proteid digestion.

b. The Ectoplasm. As in the majority of holo- and heterotrichida the ectoplasmic modifications are well differentiated from the endoplasm. A cuticle and underlying cortical plasm may be made out, the latter consisting of a much more dense substance than the endoplasm, analogous, probably, to the ectoplasm of an amoba. In it are embedded the characteristic trichocysts which ordinarily project ever so slightly from the surface, giving rise to the minute papillæ which may be distinguished in profile between the furrows of the cilia (shown in Fig. 20). In Paramxcium taken fresh from the pond water, the fixing agent which I have used, preserves the trichocysts within the cortical plasm, but after a few months under cultivation these organs cannot be made out, and seem to have been discharged and lost under the stimulation of the fixing fluid. Wallengren believes that they are taken into the endoplasm and digested as food in starving forms, but in preparations made from my cultures they are absent in the well-fed forms as in the degenerate ones. In all cases the spaces that were occupied by the trichocysts are present in the cortical plasm as vacuoles, and it is in this state that the relation to the peripheral papillæ can be easily made out (cf. Figs. I3, I 8,20 
and 21). The difficulty appears to be that the cortical plasm is incapable of holding the trichocyst threads after expulsion, for the threads may be easily seen as a cloud around the animal immediately after fixation, while the after-treatment always dislodges them in the cultivated forms, but not in the wild forms.

c. The Macronucleus. The structure of the normal macronucleus of Paramacium aurelia was described by Hertwig in I 889 and the nucleus of $P$. caudatum agrees so closely with it, that further details are hardly necessary. It is an elongate, ellipsoidal body, usually with a smooth contour and without breaks of any kind save the minute impression made by the micronucleus. It frequently lies in a vacuole which is caused by the action of the fixing fluids, for in life the macronucleus is in immediate contact with the endoplasm. The contraction is probably in the endoplasm away from the nucleus rather than a contraction of the latter. Often there is a depression in the macronucleus due to the pressure of the contractile vacuole, and food vacuoles may also press against it, as Wallengren suggests, and distort it out of the normal proportions.

In its finer structure the macronucleus is granular with the irregular granules densely packed together, giving the appearance of a homogeneous mass.

d. The Micronucleus. The micronucleus is usually embedded in the material of the larger nucleus, but may be separated from the latter, even in the resting stages, by a considerable distance, while in the dividing stages it is usually separated. Its finer structure consists of a more or less homogeneous mass of chromatin frequently arranged in lines, while at one end is an accumulation of "achromatic" material in regard to which there is some difference of opinion. In size the micronucleus is about I I microns, but in the different phases the size differs so that this characteristic has but little weight.

$e$. The Contractile Vacuoles. In the normal individual these are situated in the anterior and the posterior parts of the body, and about one-third of the length of the body from the ends. They are fed by radiating canals which are conspicuous in the living animals. The pulsation is regular as a rule, but this becomes 
spasmodic after prolonged captivity under a cover glass, and the irregularity is an index of the ultimate disintegration.

\section{Structure of Paramecium in Depression Periods.}

a. Starvation and its Effects. The periodic depressions which were noted in the experiments, and which appeared at more or less regular intervals (viz: about every six months) were noteworthy because not always accompanied by the same type of degeneration as that characteristic of starved forms.

A most comprehensive study of the structures of starved Paramacium was made by Wallengren, while various observers have called attention to the characteristic vacuolization which the cell protoplasm undergoes during starvation or at degeneration periods in any culture. In general, Wallengren found that the animals first use up the food material that is stored in granular form, in the endoplasm, and that when this reserve is used, the animals in lieu of other food, burn up first their endoplasm and then the cortical plasm. There results from this destruction, great vacuoles in the cell body which increase in size until the entire organism is distorted through the pressure of one confluent, or two or three great vesicles. Wallengren obtained his material by transferring the Paramocia to tap water again and again, and thus ridding the medium of the customary bacterial food in a very short time. My own experiments to this end consisted in leaving the ciliates in a culture glass such as I have used throughout my experiments, until all the bacteria had been eaten and the culture medium had cleared. Thus a hundred or more individuals would be left for a period of a month or six weeks in the culture chambers where evaporation was prevented, and here they were watched daily until they ultimately died of starvation. While Wallengren's experiments were undertaken for the purpose of determining the effect of starvation upon all of the protoplasmic structures of these forms, mine were done for the purpose of studying the effects of such treatment upon the nucleus and endoplasm, and general vitality. Wallengren found the following effects in the protoplasm of Paramecium after starvation for a period of from 8 to Io days, which he designates as the "first 
period" in the inanition phenomena: "All gastric vacuoles and food balls disappear during the first period. After this the small endoplasmic granules are used. As a result of this the quantity of endoplasm becomes much reduced. Toward the end of this time the living substance of the endoplasm itself is used, in part at least, to supply fuel for the continuing metabolism. Owing to the disappearance of the inclusions of the endoplasm and to the use of endoplasmic substance itself, the body form becomes more or less distorted or changed. But even in those individuals in which this has taken place and in which the form is considerably changed, the ectoplasm with its trichocysts, the contractile vacuole and the cilia are not altered in any noticeable manner. This shows, therefore, that in the first period of inanition the first materials to be used are the reserve stuffs which are normally utilized for the ordinary fuel (life processes). Only when all of the reserve material is used and when the endoplasm itself is first attacked, and only when all food whatsoever is gone, will other parts of the protoplasmic structures be attacked. When this time comes the second period is inaugurated." (Loc. cit., p. 87.)

In the second period of inanition there are more fundamental changes, and the remainder of the protoplasmic structures are involved. Ultimately the nucleus is affected and when this goes the organisms are doomed. Wallengren's conclusions as to this period are as follows: "The endoplasm, which at the beginning of this last period was already considerably reduced, now appears strongly vacuolized. The shining vacuoles which are probably filled with the products of degeneration of the endoplasmic contents, may attain to a considerable size. Along with this vacuolization the ectoplasm becomes more and more absorbed and as a result of this, the trichocysts are drawn into the endoplasm streams and are probably digested. Along with them the small papilliform swellings on the outer surface disappear, and with these the small granules which in the living animal stain with neutral red. The contractile vacuoles and their feeding canals become reduced in the same proportion as the thinning of the ectoplasm. A number of cilia are probably absorbed as a result of the decreasing size of the whole animal, and the remainder of 
them are shorter than the normal. Owing to the inner changes the whole organism may at this time be so modified that it is unrecognizable."

"Thus during the continued inanition of the body, first one part and then another becomes absorbed, first the endoplasm, next the ectoplasm, the trichocysts and the cilia in part, all to maintain as long as is possible the vital functions. In the meantime, however, the nucleus has not escaped without changes as follows:" (loc. cit., p. 98) . . . "In the inside of the macronucleus a rounded mulberry-like mass is developed. Its alveolar structure has changed at the same time, and in the center there are usually one or two small central bodies (Binnenkörper). The high pressure which is developed in the decreasing body form and due to the enlarging vacuoles, causes the nucleus to become greatly deformed and compressed. The various parts of the nucleus are broken up into fragments which may probably be used more or less as food (?). Of the former large macronucleus there is now left unchanged only the nuclear body which has been formed and this lies between the broken down nuclear parts." (Id., p. II2.) "In the micronucleus no destructive changes are manifested during the hunger degeneration. It is the one part of the body which is apparently not affected by the conditions of the experiments, a not unnatural result considering the importance which this organ of these cells has in rebuilding the macronucleus after conjugation. Of all organoids the micronucleus would thus seem to be the most important of the cell." (Id., p. I I4.)

These careful observations and clear results of Wallengren, most of which I have been able to verify, offer a good basis for the comparison of structures obtained in the different stages of the life history of Paramecium ( $c f$. Figs. 22 and 23). We may distinguish two types of degeneration changes in the series from the start to the finish. One set accompanies starvation, and was characteristic of the first two periods of depression, the other accompanies physiological depression of a different type at the last two periods. In the former the changes in structure had to do mainly with vacuolization of the endoplasm and rupture of the macronucleus, while in the latter the endoplasmic portions were 
degenerated in a different way. The ectoplasmic parts and the micronuclear structures were not affected until the last depression period.

The first clearly marked period of depression came in July, about six months after the cultures were started. It was characterized by a well-defined reduction in size (down to 109 microns; see Fig. 3), and by vacuolization of the endoplasm while the ectoplasm did not appear to be much involved. Many of the individuals were characterized by great vacuoles similar to those in starved forms, which distorted the body almost out of recognition, in others the nuclei were fragmented into two or three parts, and in all there was a marked absence of the larger food granules and gastric vacuoles which characterize the normal animals, and this, notwithstanding the fact that bacterial food was present in abundance (see Studies I). As stated in these Studies (III) the organisms under these conditions still take food and in some cases the endoplasm appears opaque with the undigested food balls, but the decrease in size continues and the endoplasmic vacuolization is not prevented by the presence of the food. It is the digestive function, apparently, which becomes ineffective at such periods, and if this is a correct assumption, this function can be stimulated, as I have shown by the experiments.

Identical results were obtained in the period of depression in December, I90I, a depression which was again overcome by the use of beef extract, while the individuals of the series which had been continued on the hay diet, all died. These became smaller and smaller, and again gave morphological indications of starvation, notwithstanding the fact that the individuals which had been stimulated with the beef extract were living and reproducing normally in the same food medium. They became much reduced in size, the endoplasm became distorted with vacuoles, and they died with absolutely no indication of disease through parasites.

These observations show, therefore, that starvation effects may be produced even though the animals are living in a medium rich in food. It is trite to say that to prevent starvation we must have not only food but the ability to digest and assimilate it, yet common as this observation is, it is important in the present connec- 
tion and involves a factor which cannot be overlooked in any discussion on old age.

In the June period, as stated previously, the same conditions were not observed, for the organisms, in part at least, had been treated with the beef extract every week during the first three months, since the previous period of depression. The division rate began to run down in the case of the B series in April, in the A series in May, and in all of the material that had been continued on the beef, the characteristic structure was a densely granular endoplasm (Fig. 7). In the specimens that had not been treated with the beef since the preceding December, this character of the endoplasm was not noted. These unstimulated individuals died out in about the 508th generation (B series) after becoming much emaciated and reduced in size, and with reduced nuclei. The nature of the protoplasmic changes is indicated, in one case at least, in Fig. I4. Here the macronucleus has entirely disappeared, not even a granular trace remaining, while the endoplasm is crowded with vacuoles of considerable size. The micronucleus is slightly hypertrophied and has a very peculiar outer membrane within which the chromatin and achromatic material lie in what appears to be the real nuclear membrane. The dense granules characteristic of the beef-fed individuals are absent. The unstimulated A series did not die out until about two weeks later. At the time when the $\mathrm{B}$ individual described above died (May I2) the unstimulated $A$ series was characterized by somewhat reduced size, a declining division rate, and absence of the dense protoplasmic granules. In the stimulated A series, on the other hand, (AI and $A_{2}$ ) of about the 560 th generation, the structures were normal, gastric vacuoles were numerous and divisions were frequent. Towards the end of June, however, when the A series nearly died out in the 62oth generation, the conditions were very different. Fig. 7 is from a specimen in the 615 th generation. Its size is below the normal; its endoplasm is choked up with granules and there is no trace of vacuoles save the contractile vacuole near one end. The macronucleus is definitely granular, and its contour is irregular as though devo:d of nuclear membrane. The micronucleus is elongate and spindle-formed. The ectoplasm is 
not deformed and save for the absence of trichocysts it appears to be normal. This was the condition of the protoplasm when the usual large number of culture individuals was reduced to $6 \mathrm{~A}$ 's and no B's, and a condition from which the A series were rescued only with the greatest difficulty by the use of pancreas extract. Figs. 8, 9 and Io represent individuals that had been in extract of pancreas for 48 hours, and then transferred to hay infusion. They are identical, therefore, with the individuals that lived and carried the race to the $742 \mathrm{~d}$ generation. In these forms the endoplasm in most cases is normally vesicular in the center and gastric vacuoles are common, while the ends alone still retain the dense granular aspect.

From this time until the race died out the division rate was sluggish. The conditions of the protoplasm in the later individuals was decidedly characteristic (Figs. 17, 19, 20, 2 I and 22). Throughout the fall, individuals would appear with densely granular protoplasm, which is invariably the sign of death, unless the animals are stimulated in some way. In such forms the macronucleus may or may not be normal, whereas the micronucleus as a rule becomes hypertrophied and the ectoplasm full of great vacuoles. Fig. 22 is a good representation of the conditions at this time. The endoplasm is apparently normal; there are food vacuoles and endoplasmic granules, and vesicular structure, but the micronucleus is spherical and vesicular, has lost its usual place in a niche in the macronucleus and shows evidence of granular modification of the previously homogeneous chromatin.

The sister-cell of the one pictured in Fig. 22, and one of the two oldest of the A series ( $74^{2}$ generations), showed the following points while alive: "A 2 , was alive this morning and was picked out for examination. It had two contractile vacuoles situated dorsally and close together. The astral canals were absent; in their place was a row of dorsal feeding canals, such as those characteristic of the more generalized holotrichida (e.g., Cblamydodontida). The rest of the body contained eight or ten large vacuoles not contractile. The macronucleus was slightly hypertrophied, and visible, indicating the approach of disintegration. 
The papillæ of the cuticle were plainly visible and what I have taken to be apertures of the trichocysts were more or less numerous. (This is shown in the preserved sister-cell, Fig. 22.) A few trichocysts remained in the cortical plasm, but there were many vacuoles in this layer indicating that when the trichocysts were discharged they were not re-formed. The peristome was normal and the mouth had a vigorous oral membrane. The size was large, fully as great as any of the preparations that had been made at any time during the 742 generations. Movements vigorous to slow, with a tendency on the part of the animal to remain stationary." ${ }_{1}$

It was while the organisms were in this structural condition that the many attempts to rejuvenate the race were made as described in the previous pages, and it was in this condition of the protoplasm that the race finally died out from exhaustion. Before dying, however, the individuals, as indicated in the above paragraph from my notes, were of full size and were filled with gastric vacuoles and partly digested food, while the body form was normal, (compare Figs. 2 and 2r).

It must be admitted that these forms were capable of individual growth at this period and, since the macronucleus was normal in the last individuals while the micronucleus was considerably changed, it must be further admitted that the vegetative metabolic processes were presumably reinvigorated; on the other band, the functions of reproduction; that is, of division, were degenerated possibly, if not probably, because of the apparent degeneration of the micronucleus and of the cortical plasm, whose functions were not reinvigorated by the artificial means which were tried.

\section{GENERAL DISCUSSION.}

Although only a beginning has been made to determine the objects for which this series of experiments was started, it is advisable to bring together the results thus far attained and to see how they conform with the a priori conceptions which were current at the outset of the experiments.

\footnotetext{
${ }^{1}$ From my note book.
} 
It is not out of place to consider first the initial objects of the undertaking, although at the risk of again repeating what has been often stated.

r. The first aim of the experiments was to get light upon the general phenomenon of conjugation and through this, upon fertilization in general.

2. To determine whether conjugation is imperatively necessary for rejuvenescence.

3. To determine whether artificial rejuvenescence is possible.

4. To determine the conditions, antecedent and subsequent to conjugation.

5. To determine, if possible, the significance of rejuvenescence.

6. To determine, finally, whether protoplasm in these simple forms is capable of indefinitely continued life without conjugation, or whether it is subject to the conditions of "old age."

On none of these points can a definitely positive answer be given, and further experiments must be undertaken to clear them up. The fact that, after a continuous cultivation of 742 generations, covering a period of 23 months, the race died out apparently from exhaustion, shows that under the conditions, continued life was impossible, and if this conclusion, which seems to be the only one justified by the results, be granted to obtain in nature, then we must agree with Maupas and others that the indefinite continuance of life without conjugation, is improbable.

\section{The Conditions of the Experiments.}

The question has been raised whether the conditions under which the experiments were undertaken were in any way abnormal to Paramacium, and whether, from the results obtained, we are justified in carrying the conclusions to the free-living forms, and to similar types in general.

It might be objected that the space allowed was inadequate; or, that the light conditions were abnormal; or, that the water would get foul; or, that they were given only one kind of food; or, that they were subjected to pressure. If we examine these objections critically we shall find that they have little basis.

Let us consider first the matter of space, for this involves some of the other objections, viz: pressure, volume conditions, and the 
like. The actual amount of water that was used for each isolated individual was one-half a cubic centimeter. This was contained in a small.chamber consisting of a hollow-ground slide, two glass supports about $3 \mathrm{~mm}$. thick, and a thin glass cover. The Paramacium had ample room, therefore, for free movement, and an actual depth of water of more than an eighth of an inch. Pressure, therefore, was out of the question. In such a slide chamber individuals were kept (i.e., extra individuals from the "stock") for periods considerably longer than six weeks without change of water, showing that the mere quantity was sufficient in order to keep the animals alive. Foulness of the water, accumulation of carbon dioxid, lack of oxygen, etc., were all guarded against by the almost daily transfer of the culture individuals into fresh hay infusion. The salt content of the water remained practically constant, for fresh hay infusion was used each time with the same amount of hay from the same source while the weekly analysis of Croton water shows only minor fluctuations in the small quantity of salts in solution. The gradual decrease in vitality cannot be attributed to these causes, a similar phenomenon being a matter of common observation and noticeable in any culture of protozoa, no matter how large the vessel, nor what the species. The light conditions were similar to those in any laboratory, the culture vessels being kept before a window with north exposure.

In regard to the possible objection that the Paramecium obtained only one kind of food, and therefore that the conditions were abnormal in this respect, it may be stated that such a condition of treatment is a sine qua non of the experiments, and the only possible means of controlling the results, and as I have demonstrated, it is by a change of diet, including salt constituents, that the periods of depression are overcome. This objection, therefore, begs the question of an object of the investigation.

It seems quite unnecessary to repeat again that the only normal life possible to Paramecium caudatum is in the ponds where it is subject to the changes in chemical composition of the water, to the exigencies of drought, of heat, of freezing, and of rest by encystment or lack of food. In the laboratory the protoplasmic activities get no rest, but day after day they are maintained at the 
optimum rate and such conditions can by no stretch of the imagination be called identical with those of the ponds. Yet the "normal conditions" may, after all, be but a matter of definition. If we leave a hay infusion to stand exposed to the air, Paramacium will ultimately appear in it, and will ultimately die out from it. The appearance and disappearance cannot be called artificial, it is as much normal for Paramacium to appear in such an infusion as it is normal for the bacteria upon which the animals feed to be there. City life for man may be called an artificial life as opposed to the "normal" original or pastoral life, but it is no less normal now than the primitive life was, even if it is found that the average length of life is shorter for urban than for country-dwelling people. The course of human life, or the history of the race, physiologically speaking, is no less normal for being rapid. In the same way we may argue for the race of Paramecium and its life in the culture chambers of the laboratory. The life pursues a normal course, although possibly faster than in nature, and the ultimate results obtained in cultures may be confidently expected to obtain sooner or later in the natural habitats. Seven hundred and fortytwo generations represent a long time for organisms to live and develop in a medium that is not normal, and the mere fact that they do so live is sufficient evidence to prove the point. It seems to me, therefore, perfectly legitimate to take the phenomena of vitality in Paramocium in culture as practically identical in outcome with the phenomena in natural surroundings, and as indicative of what goes on in living protoplasm under "normal conditions."

Looked at from this point of view, the experiments teach (I) that a given form together with the race derived from it will exhibit periodic depressions in vital activity; (2) That such depressions can be overcome by artificial means (and probably but not surely, in nature by opportune changes in the immediate environment). Further than this, however, the experiments teach, (3) that these depressions are not all of the same type, nor due to the same causes. They give reason for the belief that periods of depression may ensue wherein different functions give out, and that when this occurs, as for example when the cortical 
plasm and micronucleus show evidences of degeneration, all of the experiments that we may try to artificially reinvigorate them, will probably be futile. This may indicate one of two things, viz: that under natural conditions changes in immediate environment would be insufficient to rejuvenate when the organisms are in this ultimate state of exhaustion, unless, indeed, the experiments failed to eliminate all of the chances such an organism has in nature; or, conjugation is a necessary condition of continued protoplasmic activity.

I am inclined to the belief that some material might ultimately have been found which would have helped the Paramacia over this period of extremity and would have stimulated micronucleus and cortical plasm to continued work. The failure to find it, however, indicates a like difficulty in nature and makes the a priori reason most probable that the phenomena with which we are familiar, namely, the processes of conjugation, have been essential in maintaining the races of Paramccium up to the present time, and in keeping them from extinction.

\section{Does Protoplasm Grow Old?}

The above considerations lead to the discussion of age in a simple cell organism. In higher forms old age is manifested by the gradual weakening of the vital functions, waste matters are inadequately disposed of, or are retained in one form or another in the cells and tissues; this involves the physical impairment of organs and enhances the difficulties of their functional activities until, by the accumulation of such mutually aggravating processes, the organism ultimately dies of "old age." In Paranccium there is little morphological evidence of the onset of old age, although, if we accept the impairment of the vital functions as an index, we must conclude that diminution of the division rate, decrease in size, etc., are evidences of this phenomenon in protozoa. So far as the accumulation of waste matters is concerned, there is morphological evidence to indicate that this takes place more frequently at periods of depression. There was no sign of the crystals which frequently accumulate in the protoplasm of various protozoa, and in the last specimens of the race ( $742 \mathrm{~d}$ generation) both endoplasm and macronucleus were normal in structure. 
The surest evidence of what may be considered old age in this form, was therefore, functional, and was expressed by diminished division rate and by the increased frequency of $a b-$ normal binary fission. Abnormal division, as a matter of fact, like nuclear hypertrophy, may occur at all periods and marks some particular weakness of the single individual; occurring more frequently, however, at certain periods of depression, such abnormalities give evidence of general protoplasmic weakness. The various types of incomplete division are very instructive and a more prolonged study than I was able to give to them might afford positive evidence of the nature of the pathological changes involved. In some of the specimens which I obtained during periods of depression, the macronuclei and micronuclei appear normal; in others there is a macronucleus in each of the daughter individuals, but the micronucleus is undivided; in others the macronucleus is divided but remains in one individual, the micronucleus is undivided and remains with the original macronucleus, while the daughter individual has no trace of nuclei. In all cases, finally, of pathological division the cortical plasm appears abnormal and vacuolar, while the endoplasm is very frequently disintegrated and abnormal (Figs. 25 and 26).

While these observations are too few to permit far-reaching conclusions, they are sufficient to indicate that some protoplasmic changes have taken place, and further, that the cortical plasm has become modified in some way. Indeed, the inability completely to divide may be accounted for by the loss of vitality in this particular part of the protoplasm, for in the majority of cases the initial stages of division are safely passed, the final separation alone being retarded and usually omitted altogether, so that monsters of three or four individuals may be formed through the continued incomplete division of the original degenerate specimen (Fig. 25). As is well known, the cortical plasm is the seat of the myoneme formation, of the cilia, and of other motile organs, and, in general, may be said to possess kinetic or motor functions. That this portion of the protoplasm is subject to change is shown by the fact that at certain times the outer protoplasm becomes 
sticky or plastic and to such an extent that two individuals upon meeting, fuse together in plastogamy. This, which I have termed elsewhere the "miscible state," may be so marked that groups consisting often of from five to eight aggregated individuals are occasionally seen. It is analogous, apparently, to the plastogamy so often seen in the fresh water testacea such as Difflugia or Arcella, which Schaudinn has recently shown to have no connection with conjugation in these instances. In Paramacium during this miscible state, conjugations are for the only times possible, and many complete conjugations are found together with the fused multiple individuals. There is no doubt, then, that the cortical plasm changes in physical condition, and there is equal reason to believe that at periods of depression when these abnormal divisions are more frequent, the cortical plasm shows degenerate conditions, or, possibly, a condition of old age.

There is therefore some significance in the fact that the cortical plasm gives out; some significance connected with the diminishing division rate and with advancing old age as evidenced by diminishing activity.

While there may be some uncertainty as to whether the decreasing vitality of a race of Paramcecium is evidence of normally decreasing functions indicative of protoplasmic old age, or of some other cause of degeneration, there is absolutely no reason to believe that it is due to a parasite of any kind, nor to any harmful substances in the medium in which they live. In the earlier periods of depression there seems to have been a gradual loss of powers connected with metabolism, and of something which was vitally important to the race, for unless the individuals were stimulated, they inevitably died. This was strikingly demonstrated in the period of depression in December, I90I, when a number of individuals of the regular series were continued on the usual hay infusion, while others were treated with beef extract for 24 hours, and still others with salts of different kinds for not more than 30 minutes. The non-stimulated forms showed increasing sluggishness and depression, and all died in the course of two weeks, while the sister-cells which had been stimulated, lived with varying fortunes until a year from then (see Diagram I). The pertinent 
questions may be asked was it old age from which the organism died ? and, if so, what form did it take? They were fed daily with the same food upon which the stimulated sister cells thrived, but they could not assimilate it and would not grow nor divide. In similar cultures which had been carried to a like point by previous observers, the entire race died, and although no evidence of structural degeneration was evident, it has been taken for granted that their organisms died from exhausted vitality, or in other words, of old age. In my cultures there was some evidence of degeneration, especially in the endoplasmic structures and in the macronucleus.

The fact that stimulation was successful in carrying the race through this earlier period of depression indicates either that the conditions are not the same as those accompanying old age in metazoa, or else that such conditions may be satisfactorily overcome. I believe the conditions are more or less the same in both cases, and that in senile Paramacia certain functions have become retarded, possibly by the accumulation of useless protoplasmic elements too minute to be detected, or by some less mechanical cause connected with the molecular structure of protoplasm and which, therefore, affords no morphological evidence of change. Such an hypothesis would explain the difference in length of time required to get positive results in the stimulation experiments. For example, in August, I90I, after the race had been on hay infusion continuously for 7 months, it was necessary to keep the single individuals on beef extract for three weeks before they would live again in the hay infusion. But in December it was necessary to keep them on the stimulant only a day or two to get the desired result. The short treatment at this period sufficed, because they were not allowed to become weakened to the same extent as in the preceding period of depression. This result points to some physical condition of the protoplasm, possibly to the accumulation of some protoplasmic product or products which lead to diminished vigor and to death. Reinvigoration after a more or less prolonged treatment with the beef extract and stimulation by this and other means indicates that such materials are disposed of, or, more generally speaking, and to use a phrase which 
Wilson in $\mathcal{T}$ be Cell attributes to O. Hertwig, that the condition of stability is changed into one of protoplasmic lability.

While such an hypothesis accounts for the first two periods of depression, it fails to account for that of June and of December, I902. In the interval between June and the preceding December, the race in part, had been treated weekly with beef extract until the first of April, after which the organisms had been fed with the usual hay infusion. In June they began to degenerate, and from this time on, treatment with the beef extract was futile. and the race was finally saved only by using extract of pancreas and of brain. This, however, gave only temporary relief and complete activity was never again recovered and the division rate remained below the average, until the race finally became extinct in December, 1902, and this despite the fact that, morphologically, the endoplasm and macronucleus were restored.

Was the last period of depression running from June until December, I902, an expression of old age? From the structures of the organism and their behavior, there is no doubt that the ailment at this period was different from that of the earlier periods of depression, and there is no doubt again that the remedies which had succeeded at the earlier periods failed completely at this. The final depression of vital activities may be accounted for by one of two assumptions: (I) There was an accumulation of waste material of a different kind from that of the earlier periods, or a different physical condition, and a weakening of different functions, or (2) certain elements in the protoplasm endowed with a given potential of activity used up that potential and failed to recover it by artificial stimulation. Or a third hypothesis may be conceived which embodies both of these. The morphological structure at the final period shows that some different elements of the body were involved in the last period of depression, and that the elements which had given out in the previous periods were satisfactorily reinvigorated even in the last individuals of the race. Thus the micronucleus and the cortical plasm showed unmistakable signs of degeneration in the last few individuals of the race, while the endoplasm and macronucleus were perfectly normal in appearance, and metabolism, which these elements of 
the cell appear to control, seemed to be equally normal, since the organisms were of full size, while the endoplasm was full of partly digested food. It appears, then, that the experiments were successful in reinvigorating the elements of the cell that had given out in previous periods of depression, but that other elements were now involved which all my experiments failed to reach. Here a more deeply-lying malady had to be met, and the experiments being unsuccessful in meeting it, the entire race died out. This series of facts appears to warrant the assumption that there is a fundamental difference in the protoplasmic elements which go to make up the body of a protozoon, one of which is to be compared with the somatic cells of metazoa, the other with germ cells; the one connected with the vegetative functions of metabolism, the other with reproduction; the one may give out and so lead to "physiological death" (Hertwig) or it may be restimulated; the other may give out and so lead to "germinal death" of the race.

It is not outside the range of possibility that the last depression period might have been overcome by some suitable experiments, and the fact that we did not succeed in finding a suitable stimulant does not justify us in assuming that this period represents the last vital spark of this protoplasm, any more than we are justified in assuming that the earlier periods of depression represented this condition. If, however, some element or elements of the protoplasm become exhausted and all experiments to replace them fail, then we might justly speak of exhaustion or "old age" of these elements of the protoplasm and affirm that old age in one form, characterized the organisms during the first two periods of depression, while it took another form in the final period.

\section{Conjugation and Rejuvenescence.}

"Old age," then, appears to be a natural condition of living protoplasm and we may ask, is there any experimental evidence to show that this condition may be overcome by natural means?

It has been generally assumed by biologists that conjugation brings about rejuvenescence in the conjugating individuals, and so imparts to the ex-conjugants and to their immediate descendants a high potential of vigor. During the process of conjugation 
there is a complete change of materials or of protoplasmic makeup, and a thorough "reorganization," to use the excellent term proposed by Engelmann. Not only is there a new conjoint micronucleus with its chemical compounds derived from the union of two nuclei from individuals of diverse environment, but the endoplasm and cortical plasm must receive new materials through the disintegration and the absorption of the old macronucleus, and of at least three-quarters of the old micronucleus. If, as I have long maintained, there is a specific "kinetic" substance in the protozoon nucleus, a substance which in the centro-nuclei forms the division-center and which is found in the micronucleus of Paramacium, then the cytoplasm of Paramacium must receive a certain amount of "kinoplasm" at each period of conjugation and from the experiments, enough to carry the race through a complete cycle. In my cultures such reorganization by conjugation was prevented in the straight line of the experiments, and the only opportunity for reorganization came with the change in diet. This, indeed, seemed to be operative for some time, but ultimately failed, as we have seen. In the stock material, however, material left over after the individuals had been selected for the cultures, conjugation experiments were frequently tried during the course of the experiments, and the results have been given (Studies I). Some of the results are very suggestive in the present connection, for it was found that only a few of the ex-conjugants continued to live, approximately 6 per cent of them. This result may be due, as I have previously stated, to the fact that both of the gametes had been under identical conditions of food, etc., and no new substances were formed by the union of similar nuclei and protoplasm. Or the result may be due to the fact which Stevens ${ }^{1}$ calls attention to, that conjugation is an exhausting process, and that, being weakened through long cultivation in cultures, these ex-conjugants did not have sufficient vitality to recover. This suggestion does not set aside all of the difficulties, however, for we have still to explain the large number of cases where the ex-conjugants have lived

${ }^{1} N$. M. Stevens Further Studies on the Ciliate Infusoria, Lichnophora and Boveria. Arch. f. Protistenk, IIJ, 1903. 


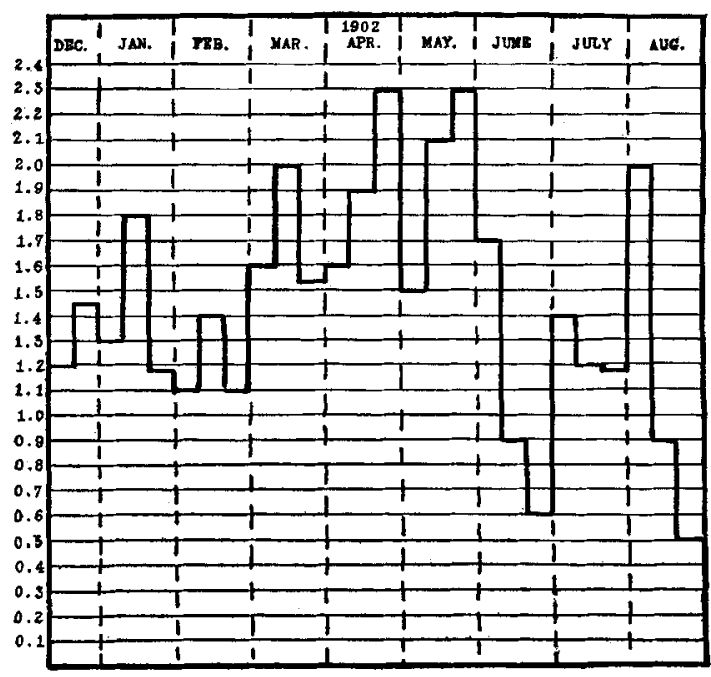

Diagram II.

Complete history of the endogamous ex-conjugant by ten-day periods. Ordinates and periods the same as in Diagram I

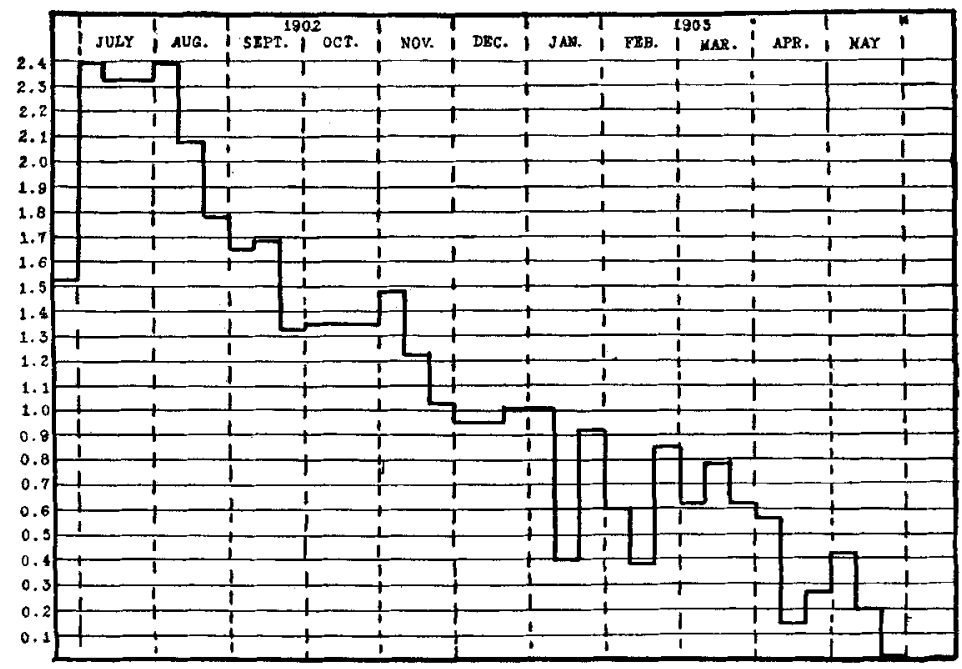

DIAGRAM III.

Complete history of the third series (C) by ten-day periods. Ordinates and periods the same as in Diagram I. As in Diagram I, this curve represents the average division rates of four lines of individuals. 
and reproduced for from 8 to 20 generations, and with apparently well-organized bodies. ${ }^{1}$

One of these successful cases was an ex-conjugant from an endogamous union of two individuals which were separated by not more than eight or ten generations from the ancestral $A$ in the $354^{\text {th }}$ generation of my cultures. The other ex-conjugant died out in the $\mathrm{I} I$ th generation, while the successful one ran through 376 generations before showing signs of debility. It went through eight months in culture without being stimulated, and died out finally at the end of 376 generations, which was exactly three generations less than the life of the third series of Paramacium (C series) which I started on June 18 , 1902, and carried along in culture until May 30, 1903, when it died out in the 379th generation (see Diagram III). ${ }^{2}$

Unfortunately, this ex-conjugant has not an absolutely clear record, for the first day after the pair had separated, I placed them both in beef extract for 24 hours (December 9, I9OI). This experiment had failed a number of times, and I had no reason to believe that it would succeed this time, and, as stated above, one of the two ex-conjugants thus treated died after eleven generations. Although at first I attributed the successful result to this treatment, I do not now believe that the beef extract had anything to do with the vigor of the race that followed, and believe that rejuvenescence was accomplished by the conjugation and nothing else. This conclusion is based upon the following facts: (1) Other ex-conjugants similarly treated with the beef extract failed to live; (2) the non-conjugating individuals of the regular series which were treated with the beef extract at the same time

\footnotetext{
${ }^{1}$ See Studies I, table of conjugations opposite p. 174.

${ }^{2}$ We have, then, the interesting coincidence of an individual running through 354 generations in culture, conjugating with one of its own close relations, and then, as an endogamous ex-conjugant, running through 376 generations more, a total of 730 generations. Against this we must set the 742 generations of the main culture series, and the 379 generations of the third series (C). The close connection between the 379 and 376 is very significant, and were it not for the fact that the first two series, $A$ and $B$, were at a fatal period of depression at the end of 200 and 190 generations. we might conclude that 370 more or less is the normal length of life of Parameccium in culture.
} 
had a lower division rate and died out before May 5; that is, after running five months (cf. Diagrams I and II). It follows, therefore, that something was operative in the ex-conjugant that was absent in the stimulated form, and this sometbing could be nothing else than the reorganization which follows conjugation. The accompanying curves show that the periods of depression and death which menaced the regular series in December, 1901, and again in June, r902, were not paralleled in the cultures of the descendants of the ex-conjugant, and the conclusion is obvious that conjugation provided some stimulus which enabled this line of Paramcecium to live through periods in which the allied races were saved only by vigorous treatment and stimulation. There is no doubt at all that, had I tried to revive the race of the ex-conjugant by beef extract at the end of August, I902, I could have done so, for there was nothing serious in the nature of the depression at this time. when I allowed them to die without making an effort to save the race. It is now a matter of deep regret to me that I did not try to save them, and see if they would live beyond the time when the allied lines died out in December, 1902. Had they done so, it would have been still more convincing proof that conjugation does actually rejuvenate and overcome the conditions of so-called "old age." I believe that the evidence which I have outlined above is quite sufficient, however, to establish this point, the one questionable factor being the beef extract, and even this, as I have shown, could have only a limited bearing and does not at all outweigh the positive evidence in favor of the conclusion.

Columbia University, April, 1904. 


\section{EXPLANATION OF PLATES.}

All of the photographs were taken by Dr. Edward Leaming from permanent preparations of Paramacium caudatum, stained with picro-carmine. All are equally magnified and the relative sizes represent absolute differences.

\section{Plate I.}

Figs. I and 2. Two normal specimens B series (107th generation and after three months of culture in hay infusion. These do not differ from typical Paramocium from the ponds, and have many endoplasmic vacuoles, alveolar protoplasm, and homogeneous nuclei.

Fig. 3. A typical individual of the B series during the first period of depression. The ectoplasm is fully as clearly defined, and as thick as in the largest forms, indicating that this portion at least, has not suffered from degeneration, a result differing from that in starved forms. (Compare Figs. 23 and 24).

Fig. 4. An individual from the B series in the 3o6th generation, stimulated with beef extract in August, fed continuously with hay infusion for three months until killed. The endoplasm is filled with gastric vacuoles and with partly digested food, the dissociated or "labile" condition of the endoplasm shown here is characteristic of Paramocium under normal conditions.

Fig. 5. An individual from the A series during the third cycle (55oth generation), and twenty-four hours after treatment with beef extract. The endoplasm is filled with gastric vacuoles, the macronucleus is normal, but the micronucleus has divided three times and a clump of six nuclei may be seen at the lower end. There is a tendency toward a denser structure of the endoplasm, especially at the two extremities, this being indicative of approaching physiological depression.

Fig. 6. An individual from the A series in the 560 th generation. Treated 48 hours before fixation with beef extract. Gastric vacuoles are abundant in the upper portion, but in the lower part the characteristic density which marks the climax of physiological depression is shown, i.e., an apparently general "loading" of the protoplasm with inert material.

Fig. 7. An individual from the A series in the $615^{\text {th }}$ generation killed at a time of general depression. It shows the typical condensed appearance when the power of division is lost and leads to death after several days without division.

Fig. 8. An individual from the A series in the $623^{\mathrm{d}}$ generation (June, 1902,) and 24 hours after successful stimulation with extract of pancreas. The condition shown in Fig, 7 has been successfully overcome, and activity renewed by this treatment. This and the two following figures show stages in the breaking up of this dense, endoplasmic mass. The macronucleus is divided while the ends alone of the animal still retain the densely granular character.

Figs. 9 and 1o. Two individuals from the A series $4^{8}$ hours after successful stimulation with pancreas extract. The endoplasm is now in a "labile" condition, although the extremities are still dense. The individual shown in Fig. Io is further advanced in recovery than that shown in Fig. 9, but both are sister cells of individuals that carried the race to the $74^{2} \mathrm{~d}$ generation.

\section{Plate II.}

Fig. II. Two individuals of the A series in the 604th generation, two weeks prior to the fatal depression of June, rgo2. These were treated with a weak solution of dibasic potassic phosphate (see paper) for 30 minutes and then transferred to hay infusion and killed 24 hours afterwards.

Fig. 12. Two individuals of the A series treated at the same time as the preceding, with a weak solution of magnesium chloride for 25 minutes. The protoplasmic structures are normal and the endoplasm has the typical alveolar appearance. 
Fig. 13. Another individual treated with potassium phosphate. The micronucleus is separated from the macronucleus. At the lower end the focus is sufficiently sharp to show the characteristic papilli-form structure of the trichocyst spaces in the ectoplasm.

Fig. 14. One of the last individuais of the B series (504th generation) in which the macronucleus is entirely gone. The micronucleus is distinct, and has its chromatin massed near one pole. The place which held the macronucleus is marked by a large vacuole. There are no observations to indicate the fate of this macronucleus, the break at the left side indicates that it may have dropped out at some period, although this did not happen during the course of the treatment, because the same condition was observed during its life, and immediately after killing.

Fig. I 5. An individual from the $\mathbf{B}$ series in the 5o2d generation after treatment with beef extract. The characteristic dense endoplasm is still present but there are many gastric vacuoles, while the micronucleus has divided three or more times and the daughter nuclei have accumulated at one end.

Fig. 16. An individual of the A series in the 6ozd generation treated for 25 minutes with phosphoric acid. It was transferred to hay infusion and killed 24 hours afterwards. The macronucleus is broken into fragments; the micronucleus has divided and one part (left center) seems to be forming a new macronucleus. (This individual offers the only evidence obtained of nuclear fragmentation and reconstruction through artificial means.)

Fig. 17. An individual from the A series in the 718 th generation, killed October 20 after living six days without division. The endoplasm shows a general absence of the larger granules, indicating starvation; the micronucleus (dimly visible at the lower end of the macronucieus) is hyaline and without chromatin, evidently degenerated.

Fig. I8. Two individuals of the A series in the $602 \mathrm{~d}$ generation, treated with a dilute solution of sodium chloride (see description), for 25 minutes. Transferred to hay infusion 24 hours afterward, and killed.

\section{Plate III.}

Figs. 19, 20, 21 and 22. Four individuals at the end period of the $A$ series. Note that in all of these the macronucleus is not abnormally large as compared with normal individuals. This was true throughout the entire race at this period and contradicts Hertwig's recent theory of the size-relations at periods of depression. Fig. Ig represents an individual in the 720 th generation, unusually small and unlike the remainder of the culture at this time. Fig. 20 represents an individual in the 725 th generation, with conspicuously dense endoplasm and macronucleus. The latter bulges out towards the observer and the effect of the ectoplasm about it is that of a special nuclear capsule. Fig. 21, an individual in the 741 st generation showing the looser texture of the endoplasm, gastric vacuoles and other characters, indicating that these organs had been restored by stimulation. The micronucleus is hypertrophied, the macronucleus is normal. Fig. 22 represents an individual in the $742 d$ generation, the oldest of the race. It shows the reorganized endoplasm, gastric vacuoles, and the like, but ectoplasm and micronucleus are degenerated. The former by vacuolization (note punctate appearance on right of macronucleus) the latter by hypertrophy and loss of chromatin.

Figs. 23 and 24. These represent individuals which were starved for two and four weeks respectively. Those in Fig. 23 were fed on beef extract August 19, transferred to hay August 2oth and left unchanged until September 19, when they were killed. The individual shown in Fig. 24 was not given beef extract, but was left in hay infusion for two weeks unchanged, when it was killed. In Fig. 23 the spots at the lower ends represent the micronuclei, in Fig. 24 the upper elongated granule is the micronucleus.

Fig. 25. A triple monster from an individual 72 hours after conjugation, with many nuclear fragments and evidence of two incomplete divisions.

Fig. 26. A double monster from the A series in September, I9or. The micronucleus is undivided, the macronucleus is deeply cleft and the individual on the right has no trace of nuclei. 


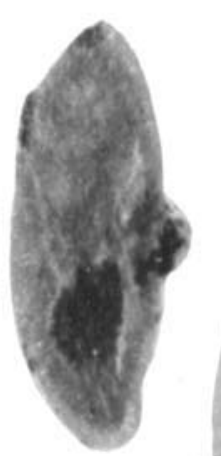

3
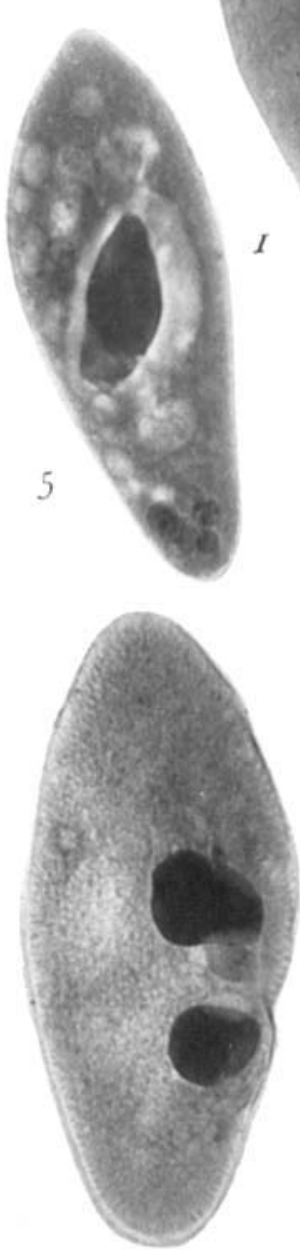

8
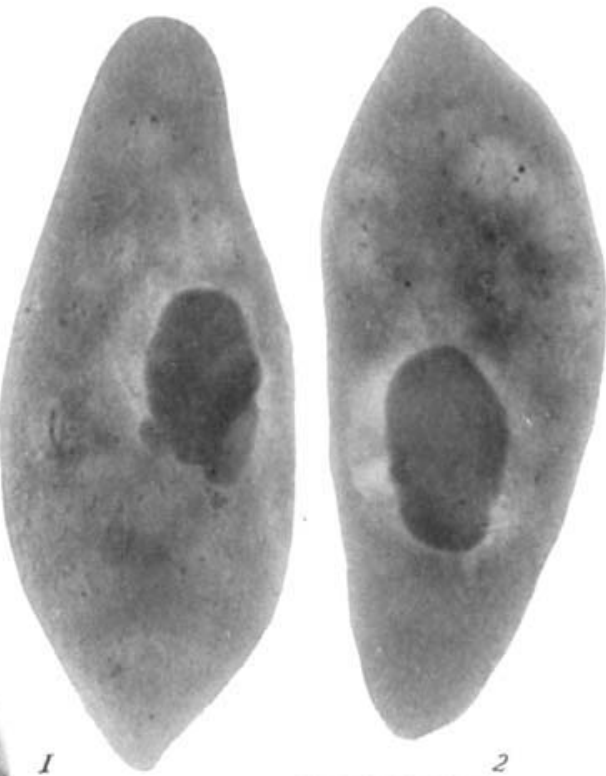

2

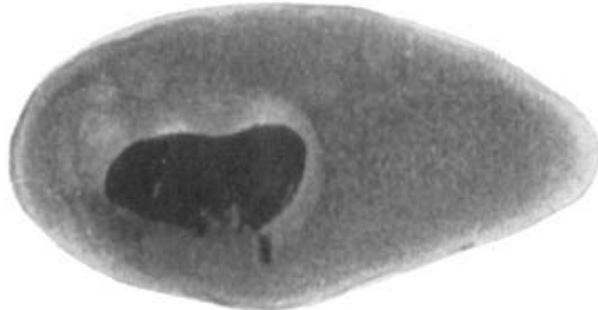

7

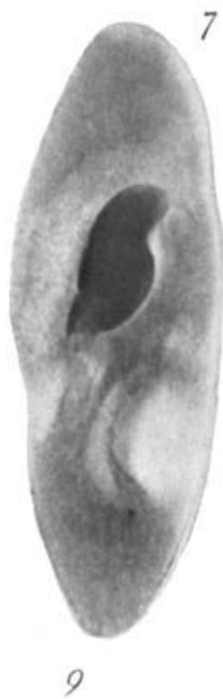

4
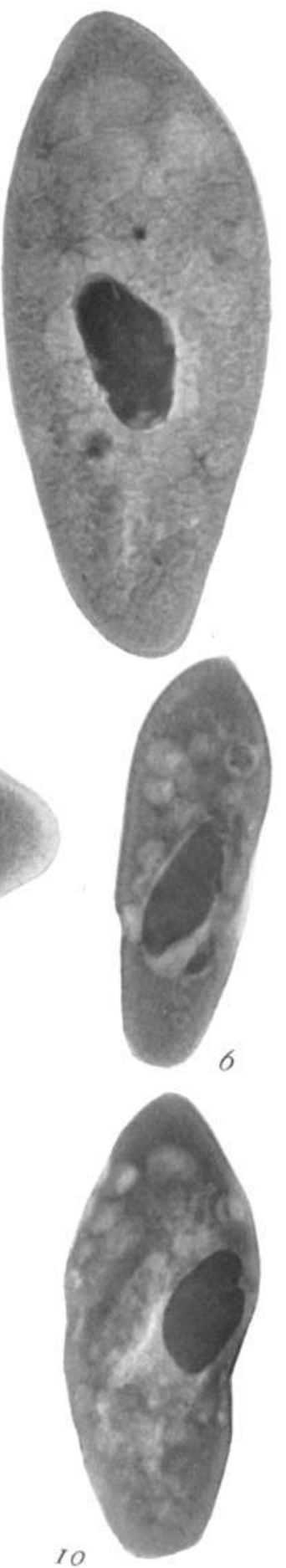

The Journal of Experimental Zoilogy 
LIFE HISTORY OF PROTYZOA. G. N. CALKINS

PLATE II
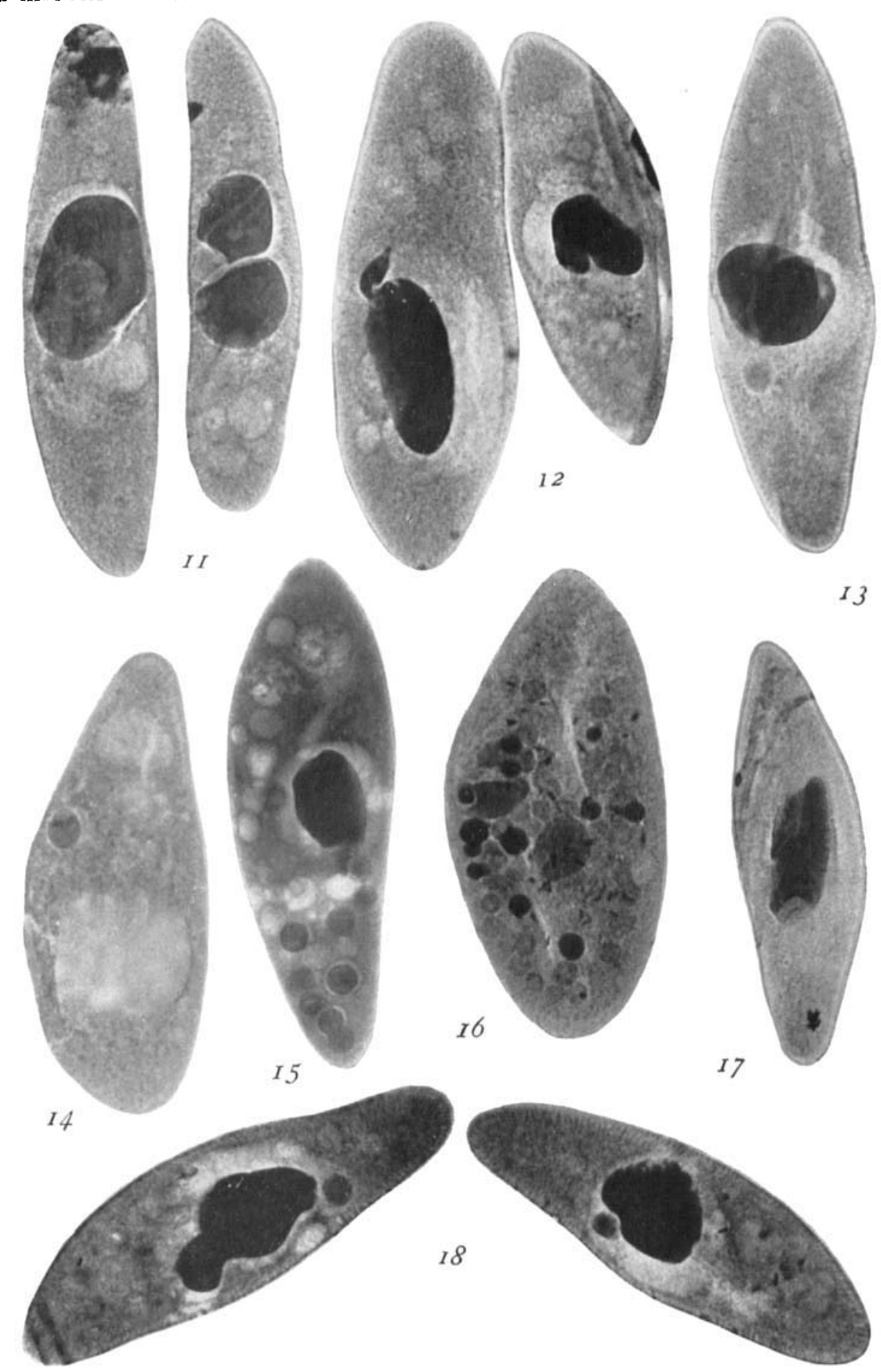

The Journal of Experimental Zoölogy 
LIFE HISTORY OF PROTOZOA. G. N. CALKINS

PLATE III

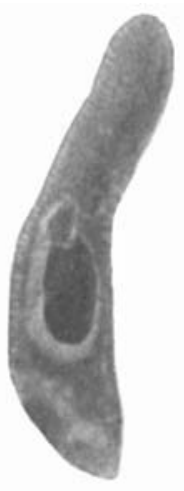

IO

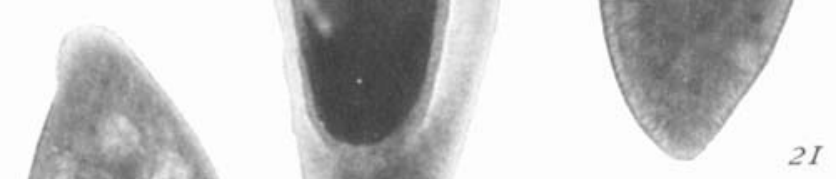

20
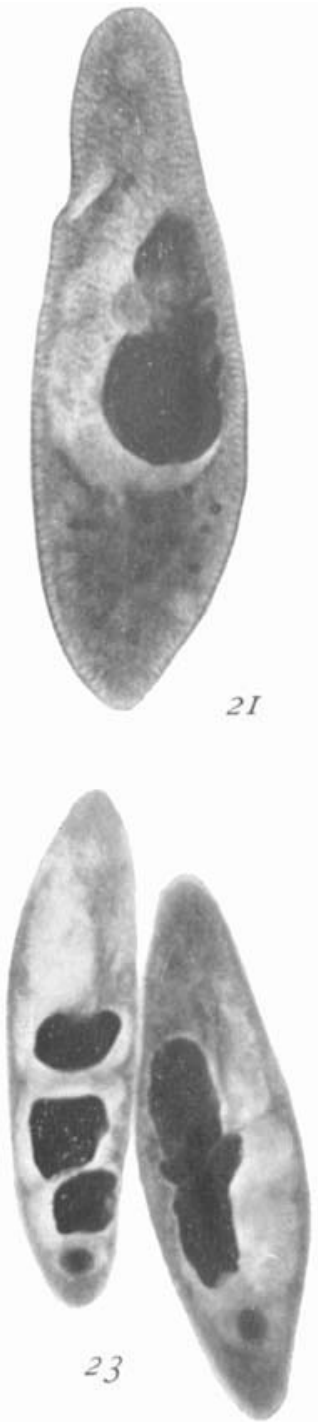

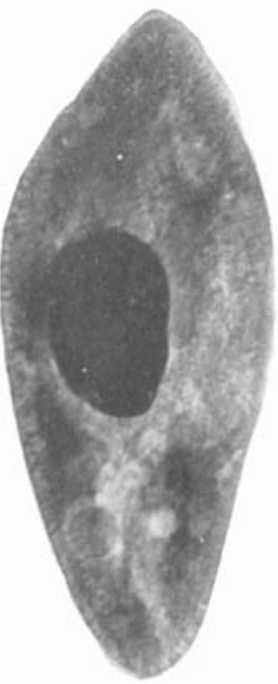

22

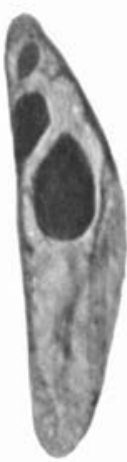

24

The Journal of Experimental Zö̈logy 